\title{
Knowledge regarding endotracheal suctioning among Nurses of a teaching hospital of Kaski District
}

\author{
Anju Lamichhane*, Dipti Koirala, Bindu Thapa, Muna Silwal \\ College of Nursing Sciences, Gandaki Medical College, Pokhara, Nepal
}

\begin{abstract}
Introduction: Endotracheal suctioning (ETS) is an essential procedure that involves removal of accumulated lung secretions from tracheobronchial tree through an artificial airway. It is crucial that this procedure is performed with professional competence based on updated scientific evidence and guidelines that guarantee efficiency and safety of the patient to prevent the common infection like ventilator associated pneumonia (VAP). Objectives: To identify the level of knowledge regarding ETS among nurses and to measure the association between knowledge level and selected demographic variables. Methods: Descriptive cross-sectional research design was adopted for this study which was conducted in Gandaki Medical College Teaching Hospital and Research Centre of Kaski, Nepal. The study population were all the nurses working in in-patient department of the hospital. Sample size was calculated through standard formula and probability simple random sampling technique was used to select 92 nurses. Semi- structured self-administered questionnaire was used to collect data. Collected data was entered, coded and edited into Statistical Package for Social Science (SPSS) version 16. Data was analyzed by employing both descriptive and inferential statistical methods. Result: Only $4.3 \%$ of the total respondents had good knowledge on ETS whereas $52.2 \%$ had fair knowledge and $43.5 \%$ had poor knowledge. There was significant association between respondent's level of knowledge on ETS and ethnicity $(p=0.049)$ and professional qualification $(p=0.028)$. Conclusion: Nearly half of the nurses had poor knowledge on ETS. Therefore, it is necessary to upgrade nurse's knowledge on ETS through inservice education programs.
\end{abstract}

Keywords: Endotracheal Suctioning, Knowledge, Nurses

\section{Correspondence to:}

Anju Lamichhane, College of Nursing Sciences

Gandaki Medical College, Pokhara, Nepal

Email: lcanju91@gmail.com

Submitted: July 19, 2020

Accepted: November 30, 2020

To cite: Lamichhane A, Koirala D, Thapa B, Silwal M. Knowledge regarding endotracheal suctioning among Nurses of a teaching hospital of Kaski District. JGMC Nepal. 2020;13(2):178-82.

DOI: $10.3126 /$ jgmcn.v13i2.30160

\section{INTRODUCTION}

Endotracheal suctioning (ETS) is an essential procedure which involves removal of accumulated lung secretions from tracheobronchial tree through an artificial airway with the help of mechanical suction device. ${ }^{1}$ ETS is an element of bronchial hygiene therapy and mechanical ventilation. ${ }^{2,3}$ It is a patientbased care that involves preparation of patient, suctioning event and post-procedure care. The primary purposes of ETS are to provide adequate oxygenation, maintain airway permeability and gaseous exchange, increase alveolar ventilation and prevent ventilator-associated pneumonia. ${ }^{4}$

It is crucial that this procedure is performed with professional competence based on updated scientific evidence and guidelines that guaranties efficiency and the safety of the patient. Nurses whose responsibility is to provide care to patients must perform ETS efficiently and effectively by maintaining sterility in order to avoid infections. ${ }^{1,5}$ Different complications such as 
cardiac and respiratory failure, hemodynamic instability, tracheobronchial injury, increased intracranial pressure and hypoxemia; especially infection Ventilator Associated Pneumonia (VAP) may occur if the procedure is performed incorrectly. ${ }^{1-6}$

In the present context, risky practices of ETS remains the global problem. Although scientific guidelines for ETS are available, many of these recommendations have not been applied in nurses' clinical practices which may be due to the lack of good knowledge. ${ }^{7}$ Regardless of established ETS evidence-based recommendations nurses rather perform procedures traditionally or routinely. ${ }^{4,8} \mathrm{~A}$ study conducted among staff nurses in Nellore revealed that $7 \%, 73 \%$ and $20 \%$ had inadequate, moderate and adequate knowledge level regarding ETS respectively. ${ }^{2}$ Similarly, another study conducted among 42 ICU nurses in Khartoum teaching hospital, Sudan identified that majority $(85.7 \%)$ had poor knowledge level on ETS. ${ }^{6}$ In the context of Nepal, Shrestha and Shrestha ${ }^{3}$ revealed that a total of $44.2 \%$ of the nurses had inadequate knowledge whereas Dahal and Kunwar ${ }^{1}$ found fair knowledge among 39.3\% of nurses regarding endotracheal suctioning. Assessment of knowledge regarding ETS among nurses working at Gandaki medical college has not been explored yet. Therefore, the researcher aimed to assess knowledge regarding ETS among nurses.

\section{METHODS}

Descriptive cross-sectional research design was adopted for this study. Gandaki Medical College Teaching Hospital and Research Centre (GMCTHRC) was selected as the setting for the study. The targeted population of the study consisted of all nurses working in in-patient department of GMCTHRC whose total number was 204. Sample size was 92 based on sample size estimation formula. Simple random sampling technique was used to select the sample from the sampling frame of 204 nurses using lottery method. All the PCL and Bachelor level nurses working for at least 3 months in inpatient department of GMCTHRC were included in the study. A semi-structured self-administered questionnaire in English language was used as an instrument which was developed on the basis of extensive review of the literature, standard recommendations and protocols for endotracheal suctioning along with consultation with experts. The instrument was organized into 2 parts:

Part I: Consisted of questions related to demographic and job-related characteristics of respondents such as nurses' age, religion, ethnicity, place of residence, marital status, professional qualification, working units, designation, duration of work experience and training.
Part II: Consisted of 22 questions related to knowledge regarding ETS, 20 of which were single response questions and 2 were multiple response questions with 4 options in each, so the total score was 28 .

The level of knowledge on ETS among nurses was categorized in 3 levels: (Elbokhary et al., 2015; Dahal \& Kunwar, 2018)

Good knowledge (22-28): > 75\%

Fair knowledge (15-21): 50-75\%

Poor knowledge (0-14): $<50 \%$

Validity of the instrument was maintained by extensive review of related literature and consultation with research advisors and subject matter expertise in the field of nursing before and during the construction of the tool.

Reliability of the tool was tested by using Split-half method in which reliability coefficient score was 0.7 indicating the tool as reliable. To identify accuracy, clarity and consistency of the tool, pretesting of the instrument was done among $10 \%$ of the sample size.

The study was carried out after the approval of the research proposal from the concerned authority of Gandaki Medical College. Informed written consent was taken from each participant after explaining the purpose of study to the respondents. None of the respondents were forced to participate in the study. Respondents' dignity and confidentiality were maintained by not disclosing the name and other information of the respondent except its use in the study. Data was collected by researcher herself from June 30 to July 13, 2019. Average of 6-8 nurses were approached from different departments in each day. The collected data was organized, coded and entered into Statistical Package for Social Science (SPSS) version 16 daily and then analyzed by employing both descriptive and inferential statistical methods. In descriptive statistics, frequencies, percentage, mean and standard deviation were calculated to analyze demographic data. In case of inferential statistics, Chi-square test, Fishers Exact Test and Likelihood Ratio was used to find the association between selected variables with knowledge score. The level of significance was considered at $5 \%$ with $p$ value $<0.05$ and $95 \%$ confidence interval.

\section{RESULTS}

Table 1 reveals the demographic and job-related characteristics of the respondents which shows the mean age of the respondents was 23.55 years (SD \pm 2.66 years). Two third of the respondents (66.3\%) belonged to age group 21-25 years. Around four-fifth of the respondents (79.3\%) were Hindus and $45.7 \%$ were Brahmin/Chhetri. Majority 
(93.5\%) were residing in urban area. More than half of the respondents $(56.5 \%)$ were unmarried. Majority of the respondents (82.6\%) had PCL level of education. Half of the respondents were working in critical units of the hospital with more than two-thirds working as staff nurse (77.2\%). More than three-fourth $(77.2 \%)$ had working experience of more than one year and very few $(8.7 \%)$ had received the training on endotracheal suctioning.

Table 1: Demographic and Job-related Characteristics of the Respondents ( $\mathbf{n = 9 2 )}$

\begin{tabular}{|c|c|c|}
\hline Variables & Number & Percentage \\
\hline \multicolumn{3}{|l|}{ Age in years } \\
\hline $15-20$ & 10 & 10.9 \\
\hline $20-25$ & 61 & 66.3 \\
\hline $25-30$ & 20 & 21.7 \\
\hline $30-35$ & 1 & 1.1 \\
\hline \multicolumn{3}{|c|}{ Mean age $\pm S D$ in years $=23.55 \pm 2.66 ;$ Min. $=18$, Max. $=30$} \\
\hline \multicolumn{3}{|l|}{ Religion } \\
\hline Hinduism & 73 & 79.3 \\
\hline Buddhism & 16 & 17.4 \\
\hline Christianity & 3 & 3.3 \\
\hline \multicolumn{3}{|l|}{ Ethnicity } \\
\hline Dalit & 7 & 7.6 \\
\hline Janjati & 43 & 46.7 \\
\hline Brahmin/Chhetri & 42 & 45.7 \\
\hline \multicolumn{3}{|l|}{ Type of Residence } \\
\hline Urban (residing in urban municipality) & 86 & 93.5 \\
\hline Rural (residing in rural municipality) & 6 & 6.5 \\
\hline \multicolumn{3}{|l|}{ Marital Status } \\
\hline Unmarried & 52 & 56.5 \\
\hline Married & 38 & 41.3 \\
\hline Divorce/Single & 2 & 2.2 \\
\hline \multicolumn{3}{|l|}{ Professional Qualification } \\
\hline PCL Nursing & 76 & 82.6 \\
\hline BN/BNS & 8 & 8.7 \\
\hline B.Sc. Nursing & 8 & 8.7 \\
\hline \multicolumn{3}{|l|}{ Working Units } \\
\hline General Units & 46 & 50.0 \\
\hline Critical Units & 46 & 50.0 \\
\hline \multicolumn{3}{|l|}{ Designation } \\
\hline Nursing Incharge & 3 & 3.3 \\
\hline Senior Staff nurse & 18 & 19.6 \\
\hline Staff Nurse & 71 & 77.2 \\
\hline \multicolumn{3}{|l|}{ Duration of Work Experience } \\
\hline$<1$ year & 21 & 22.8 \\
\hline$\geq 1$ year & 71 & 77.2 \\
\hline \multicolumn{3}{|l|}{ Training on Endotracheal Suctioning } \\
\hline Yes & 8 & 8.7 \\
\hline No & 84 & 91.3 \\
\hline
\end{tabular}

Table 2 illustrates the overall respondents' level of knowledge on endotracheal suctioning. Among 92 participants, more than half of the nurses (52.2\%) had fair knowledge with $43.5 \%$ of them having poor knowledge. Only $4.3 \%$ of the nurses had good knowledge on endotracheal suctioning.

Table 3 shows statistics of overall scoring on knowledge on ETS among nurses. The mean score of the overall knowledge on ETS was 14.33 (51.2\%).
Table 2: Overall Respondents' Level of Knowledge on Endotracheal Suctioning ( $\mathbf{n = 9 2 )}$

\begin{tabular}{lrr}
\hline Level of Knowledge & Number & Percentage \\
Good Knowledge $(>75 \%)$ & 04 & 4.3 \\
Fair Knowledge $(50-75 \%)$ & 48 & 52.2 \\
Poor Knowledge $(<50 \%)$ & 40 & 43.5 \\
\hline
\end{tabular}

Table 3: Statistics of Overall Scoring on Knowledge on ETS among Nurses $\quad(\mathbf{n}=\mathbf{9 2})$

\begin{tabular}{llllll}
\hline Variables & $\begin{array}{l}\text { Total } \\
\text { Possible } \\
\text { Score }\end{array}$ & $\begin{array}{l}\text { Mean } \\
\text { (S.D.) }\end{array}$ & Median & Minimum & Maximum \\
$\begin{array}{l}\text { Overall knowledge score } \\
\text { on ETS }\end{array}$ & 28 & $\begin{array}{l}14.33 \\
(3.6)\end{array}$ & 14 & 07 & 23 \\
$\begin{array}{l}\text { Percentage of Knowl- } \\
\text { edge score on ETS }\end{array}$ & 100 & $\begin{array}{l}51.2 \\
(12.9)\end{array}$ & 50 & 25 & 82 \\
\hline
\end{tabular}

Table 4 shows that there is statistically significant association between respondents' level of knowledge on endotracheal suctioning and their ethnicity $(p=0.049)$ and professional qualification ( $p=0.028$ ). For the ease in computing association, respondents' good and fair knowledge were merged to make a class of adequate knowledge (i.e. $\geq 50 \%$ ) whereas poor level of knowledge was classified as inadequate knowledge (i.e. $<50 \%$ ).

Table 4: Association between Respondents' Level of Knowledge on Endotracheal Suctioning and Selected Variables $(\mathbf{n}=\mathbf{9 2})$

\begin{tabular}{|c|c|c|c|c|}
\hline \multirow{2}{*}{ Variables } & \multicolumn{2}{|c|}{ Level of Knowledge } & \multirow{2}{*}{$\chi^{2}$} & \multirow{2}{*}{$p$-value } \\
\hline & $\begin{array}{l}\text { Adequate } \\
\text { No. (\%) }\end{array}$ & $\begin{array}{l}\text { Inadequate } \\
\text { No. (\%) }\end{array}$ & & \\
\hline \multicolumn{3}{|l|}{ Age (in years) } & \multirow[t]{3}{*}{0.004} & \multirow[t]{3}{*}{0.948} \\
\hline$\leq 25$ & $40(76.9)$ & $31(77.5)$ & & \\
\hline$>25$ & $12(23.1)$ & $9(22.5)$ & & \\
\hline \multicolumn{5}{|l|}{ Religion } \\
\hline Hinduism & $43(82.7)$ & $30(75)$ & \multirow[t]{3}{*}{1.098} & \multirow[t]{3}{*}{$0.578^{*}$} \\
\hline Buddhism & $8(15.4)$ & $8(20.0)$ & & \\
\hline Christianity & $1(1.9)$ & $2(5.0)$ & & \\
\hline \multicolumn{5}{|l|}{ Ethnicity } \\
\hline Dalit & $2(3.8)$ & $5(12.5)$ & \multirow[t]{3}{*}{6.034} & \multirow[t]{3}{*}{$0.049^{*}$} \\
\hline Janjati & $21(40.4)$ & $22(55.0)$ & & \\
\hline Brahmin/Chhetri & $29(55.8)$ & $13(32.5)$ & & \\
\hline \multicolumn{3}{|l|}{ Type of residence } & \multirow{3}{*}{0.228} & \multirow{3}{*}{$0.174^{\epsilon}$} \\
\hline Urban municipality & $47(90.4)$ & $39(97.5)$ & & \\
\hline Rural municipality & $5(9.6)$ & $1(2.5)$ & & \\
\hline \multicolumn{5}{|l|}{ Marital status } \\
\hline Unmarried & $29(55.8)$ & $23(57.5)$ & \multirow[t]{2}{*}{3.594} & \multirow[t]{2}{*}{$0.166^{*}$} \\
\hline Married & $23(44.2)$ & $15(37.5)$ & & \\
\hline Divorce/Single & $0(0.0)$ & $2(5.5)$ & \multirow{4}{*}{4.819} & \multirow{4}{*}{0.028} \\
\hline $\begin{array}{l}\text { Professional Quali- } \\
\text { fication }\end{array}$ & & & & \\
\hline PCL Nursing & $39(75.0)$ & 37 (92.5) & & \\
\hline Bachelor & $13(25.0)$ & $3(7.5)$ & & \\
\hline \multicolumn{3}{|l|}{ Working Unit } & \multirow[b]{2}{*}{0.000} & \multirow[b]{2}{*}{1.000} \\
\hline General Units & $26(50.0)$ & $20(50.0)$ & & \\
\hline
\end{tabular}




$\begin{array}{ccccc}\begin{array}{c}\text { Critical Units } \\ \text { Designation }\end{array} & 26(50.0) & 20(50.0) & & \\ \begin{array}{c}\text { Nursing In-charge } \\ \text { Staff Nurse }\end{array} & 2(3.8) & 0(0.0) & 0.503 & 0.317^{\epsilon} \\ \begin{array}{c}\text { Duration of Work } \\ \text { experience }\end{array} & 40(100) & & \\ <1 \text { year } & 12(23.1) & 9(22.5) & 0.004 & 0.948 \\ \geq 1 \text { year } & 40(76.9) & 31(77.5) & & \\ \text { Training on Endotracheal Suctioning } & & \\ \text { Yes } & 4(7.7) & 4(10.0) & 0.724 & 0.488^{\epsilon} \\ \text { No } & 48(92.3) & 36(90.0) & & \end{array}$

Significant level of P-value at 0.05; *Likelihood Ratio; $€$-Fishers Exact Test

\section{DISCUSSION}

The present study assessed the level of knowledge on endotracheal suctioning among 92 nurses working in general and critical units of GMCTHRC. Based on the obtained results, only $4.3 \%$ of the nurses had good knowledge whereas $52.2 \%$ and $43.5 \%$ had fair and poor knowledge respectively. These findings are in line to the study done by Elbokhary et al. $^{6}$ which revealed that only $4.8 \%$ of nurses had good knowledge level. Shrestha et $\mathrm{al}^{3}$ also found that $44.2 \%$ of Nepalese nurses working in ICU had inadequate knowledge regarding ETS. However, the findings are inconsistent with the study of Dahal and Kunwar ${ }^{1}$ in which level of knowledge was good among $60 \%$ and fair among $39.3 \%$ of nurses. This discrepancy may be due to the lack of in-service education and training on endotracheal suctioning.

Endotracheal suctioning as the 'procedure to reduce ventilator associated pneumonia' was known by $76.1 \%$ of nurses. Less than half (44.6\%) of the respondents knew that it must be done while withdrawing the catheter. Just more than one-fourth $(29.3 \%)$ of the nurses knew the nerve that is stimulated during ETS. Majority (70.7\%) of the nurses knew semi-fowlers as the best position for ETS. Less than half (48.9\%) knew the recommended duration (10-15 second) for each ETS. Around half knew the appropriate size (43.5\%), recommended pressure (58.7\%), length of suction catheter $(44.6 \%)$ and number of suctions to be performed per suctioning (30.4\%). The most important action while endotracheal suctioning is hyperoxygenation before and after the procedure. This knowledge was known to $48.9 \%$ of the respondents. The correct volume of air to inflate endotracheal tube cuff was known by $54.3 \%$ of the nurses. About one-third of the respondents (23.9\%) knew that ETS should be discontinued immediately if heart rate either increases or decreases. Majority of the nurses (84.8\%) knew that hypoxia is the most serious complication that occurs during endotracheal suctioning. Less than half of them $(46.7 \%)$ answered that a suction catheter should be disposed after single use.

There was statistically significant association of respondents' knowledge on endotracheal suctioning with their ethnicity $(p=0.049)$ and professional qualification ( $p=0.028)$. A study conducted by Shrestha, et $\mathrm{al}^{3}$ showed no association of level of knowledge with professional qualification $(p=0.424)$ and ethnicity $(p=0.481)$.

\section{CONCLUSION}

The study concludes that only few nurses had good knowledge and nearly half of the nurses had poor knowledge on ETS. The significant influencing variables for level of knowledge on ETS were professional qualification and ethnicity. Therefore, it is necessary to upgrade the nurses' knowledge on ETS through in-service education programs.

\section{ACKNOWLEDGEMENTS}

I would like to express my heartful gratitude to the principal of GMC, Prof. Dr. Rabeendra Prasad Shrestha for granting permission to conduct the study. My sincere gratitude to the Lecturer Ishwori Bhandari, GMC for his statistical guidance during data analysis. Similarly, I am grateful to all the respondents who participated in the study for their valuable time and effort.

\section{REFERENCES}

1. Dahal P, Kunwar SS. Knowledge and Practice regarding endotracheal care among the Health Professional of Shahid Gangalal National Heart Center, Bansbari, Kathmandu, Nepal. European Journal of Biomedical and Pharmaceutical Sciences. 2018;5(6):361-70.

2. Bhanu BP, Limi ED, Indira SA. Study to assess the knowledge regarding ET suctioning among staff nurses and student nurses in $\mathrm{NMCH}$, Nellore. International Journal of Applied Research. 2016;2(6):150-2.

3. Shrestha S, Shrestha R. Knowledge and Practice Regarding Endotracheal Suctioning among Nurses of Selected Teaching Hospitals, Bharatpur, Chitwan. ACTA Scientific Medical Sciences. 2018;2(6):10-16.

4. Zainib T, Afzal M, Sarwar H, Waqas A. The Gap between Knowledge and Practices in Standard Endotracheal Suctioning of Intensive Care Unit Nurses in Children's Hospital Lahore. Saudi Journal of Medical and Pharmaceutical Sciences. 2017;3(6):454-63.

5. Frota OP, Loureiro MDR, Ferreira AM. Knowledge about endotracheal suctioning on the part of intensive care nursing professionals: a descriptive study. Online Brazilian Journal of Nursing. 2013;12(2):546-54.

6. Elbokhary R, Osama A, AL-khader M. Knowledge and Practice of ICU Nurses Regarding Endotracheal 
Suctioning for Mechanically Ventilated Patients in Khartoum Teaching Hospital. American Journal of Clinical Neurology and Neurosurgery. 2015;1(2):92-8.

7. Mwakanyanga ET, Masika, GM, Tarimo, EAM. Intensive care nurses' knowledge and practice on endotracheal suctioning of the intubated patient: A quantitative cross-sectional observational study. PLOS one. 2018;13(8):1-13.

8. Negro A, Ranzani R, Villa M, Manara D. Survey of Italian ICU nurses' knowledge about endotracheal suctioning. Intensive and Critical Care Nursing. 2014;30(6):33945. 